\title{
A AMÉRICA LATINA NO SÉCULO XXI: geopolítica crítica dos Estados e os movimentos sociais, do conhecimento e da representação ${ }^{1}$
}

\author{
INTRODUÇÃO
}

\author{
Heriberto Cairo*
}

"A pergunta sobre o que significa ser latinoamericano está mudando desde começos do século XXI. Se desvanecem respostas que antes convenciam e surgem dúvidas sobre a utilidade de firmar compromissos continentais. Aumentaram as vozes que intervêm neste debate [...] Ao mesmo tempo, os Estados nacionais [...] são diminuídos pela globalização. As incertezas e regressões econômicas e políticas de fins do século XX deixaram para trás muitas expectativas. Aqueles que apostaram somente nos Estados nacionais, no mercado, ou nos meios massivos, como caminho para o desenvolvimento e a integração da América Latina, aprenderam que nenhum desses referentes é o que foi.” Com essas palavras, García Canclini (2002, p.18) começava a estabelecer diversas dúvidas em

*Professor Titular de Ciência Política e de Administração na Faculdade de Ciência Política e Sociologia da Universidad Complutense de Madrid.

Campus de Somosaguas, 28223. Madrid - España.

hcairoca@cps.ucm.es

${ }^{1}$ Agradeço o convite (e a paciência) das editoras da revista Caderno CRH, Profas. Anete B.L. Ivo e Elsa S. Kraychete para organizar este dossiê temático. Do mesmo modo, agradeço a todos os colegas que colaboraram no dossiê; e em particular a Carlos Milani, co-urdidor de tramas acadêmicas e, neste caso, grande incentivador, e a Breno Bringel, decisivo na chegada a bom porto de tudo. seu ensaio Latinoamericanos buscando lugar en este siglo, em torno da viabilidade da América Latina num mundo globalizado. Ainda nesse ensaio, o autor aborda os elementos que globalizam a região e aqueles que aprofundam seus próprios traços - mais tarde retornarei sobre a questão -, mas é significativa a pergunta-motivo que se faz: "Quem quer ser latino-americano?” García Canclini é relativamente cauteloso com respeito à resposta, mas nos recorda que o relato da América Latina deve ser polifônico. Não sei se este dossiê responde a essa exigência, provavelmente não, mas tenta problematizar algumas das visões comuns sobre a América Latina e reunir vozes e práticas habitualmente silenciadas.

\[ \star \star \star \]
Em primeiro lugar vou expor a perspectiva
geral do dossiê. Nesse sentido, é necessário afir-
mar que ela não é a dos estudos de área (area
studies), nascidos nos Estados Unidos (e em ou-
tros países ocidentais), após a Segunda Guerra
Mundial. Os estudos nessa perspectiva estão mar-


cados, desde o início, por um eurocentrismo (ou “ocidentocentrismo") muito forte, que conduz a estudar a região sempre em termos comparativos com um Ocidente desenvolvido, democrático e mais avançado. Configuram, assim, uma geografia binária, típica da visão de mundo moderna, que começa a se desenvolver no Renascimento europeu e, posteriormente, estende-se a todo o mundo. Esse é um dos elementos fundamentais da colonialidade do saber. $^{2}$

E, mesmo que os estudos de área sejam decididamente interdisciplinares - incluindo a sociologia, a geografia, a história, a economia ou a ciência política, entre outras disciplinas reconhecidas-e, nesse sentido, abram caminhos para a superação das limitações próprias dos enfoques tradicionais em ciências sociais, sua perspectiva é "imperial" (Mignolo, 2007). Para que se renovem, é necessário descolonizá-los, ou seja, superar o mencionado eurocentrismo ou o ocidentocentrismo.

A geopolítica crítica que se desenvolveu nos últimos anos pode ser útil nessa tarefa, já que permite abordar o estudo das regiões do planeta de uma forma diferente da dos estudos de área. Ela está ligada aos trabalhos pioneiros de John Agnew (2003), Simon Dalby (1990) e Géaroid Ó Tuathail (1996). Sua idéia fundamental é reconceituar a geopolítica como discurso que contribui para a

${ }^{2}$ Para o debate sobre a colonialidade do poder e do saber no Brasil, ver o texto de Lander (2005), apresentado por Carlos Walter Porto-Gonçalves.
Sharp, 2000) introduziram, mais tarde, o conceito de "geopolítica popular", referente à cultura popular, aos argumentos geopolíticos elaborados nos meios de comunicação, no cinema, na novela, que contribuem decisivamente para a produção e circulação do "sentido comum” geopolítico, dos pressupostos geopolíticos assumidos pelos cidadãos e que permitem, em boa medida, fazer "inteligível" a geopolítica prática e a formal.

Uma das características fundamentais da geopolítica crítica é a consideração de que a reflexão espacial sobre as relações de poder não se pode limitar-como ocorria na geopolítica tradicional às existentes entre os Estados. Seriam esquecidos, então, os inumeráveis fluxos que ocorrem à margem, e ela operaria de forma reducionista, limitando-se ao "político" e ao "estatal". Em conseqüência, faz-se necessário desenvolver também o que Paul Routledge (1998) denomina "anti-geopolítica", ou seja, considerar as práticas espaciais e representações do espaço dos movimentos sociais, das organizações populares e de intelectuais dissidentes que resistem, de diversas maneiras, à geopolítica dos Estados. Desse modo, ainda que a geopolítica crítica enfatize a macro-escala de análise, não abandona outras escalas, como era o caso da tradicional, para não cair num determinismo geográfico.

\section{* * *}

Se a geopolítica crítica se centra no discurso, é necessário também refletir sobre algumas questões fundamentais e elucidá-las, como, por exemplo, sua relação com os aspectos materiais e simbólicos que configuram uma região como a América Latina. O "discurso geopolítico" foi utilizado para referir-se aos enunciados sobre a disposição geográfica da política exterior dos Estados, e, inclusive, em algumas ocasiões, se inclui na definição também o conjunto de procedimentos que geram e organizam esse discurso nas elites governamentais dos Estados - ou seja, tanto os enunciados geopolíticos como sua enunciação. Uma definição precisa foi a elaborada por Agnew e Corbridge, considerando que o discurso geopolítico se refere 
à forma na qual a geografia da economia política internacional foi "escrita e lida" nas práticas das políticas econômicas e exteriores [dos Estados] ao longo de diferentes períodos de ordens geopolíticas. "Escrita" está relacionado à forma em que as representações geográficas são incorporadas nas práticas das elites políticas. "Lida" está relacionado às formas em que essas representações são comunicadas (1995, p. 46).

Em outras palavras, poder-se-ia dizer que a noção de discurso geopolítico se refere à forma como os intelectuais de Estado (intellectuals of statecraft) - esse grupo heterogêneo, tanto de "teóricos" universitários ou de institutos de pesquisa como de "praticantes", militares ou diplomatas-espacializam a política mundial.

Definir assim o discurso geopolítico permite fugir de uma dupla simplificação: a idealista, cujos enfoques textualistas tentam explicar as práticas sociais como epifenômenos da linguagem, e a determinista, que reduz o discurso a uma mera ideologia ou a um conjunto de idéias determinadas pelas práticas sociais (freqüentemente econômicas), ou que são funcionais para sua representação. Nesse sentido, o discurso geopolítico se fundamentaria na relação dialética entre as "representações do espaço" e as "práticas espaciais", como afirmava Lefebvre (1974). As práticas espaciais se referem a lugares específicos e a conjuntos espaciais inter-relacionados e organizados para a produção econômica e a reprodução social em uma dada formação social. As representações do espaço implicam signos, códigos e "entendimentos" que são necessários para fazer inteligíveis as práticas espaciais.

O conceito, também lefebvriano, de "espaços de representação" é útil para se entenderem as relações entre os discursos geopolíticos e os processos de identificação social e, em particular, os elementos que favorecem sua hegemonia, bem como as resistências que os minam, uma vez que tais espaços apresentam simbolismos complexos, unidos à parte "subterrânea” da vida social, e inspiram mudanças na representação do espaço, com o objetivo de transformar as práticas espaciais. Uma representação do espaço somente será dominante, em longo prazo, se imbricada adequadamente com as práticas espaciais dominantes, embora, em seu próprio desenvolvimen- to, sejam geradas as resistências, os espaços de representação, que podem transformar tais práticas.

A noção de discurso de Michel Foucault, tal e como é desenvolvida em dois de seus trabalhos sobre a genealogia de discursos específicos, como são o clínico (1963) e o sexual (1976), também incluiria tanto a linguagem como sua materialidade nas instituições e nas práticas sociais. O poder dos discursos, de fato, derivaria de sua institucionalização e de sua prática. Para Foucault, um discurso é um conjunto de enunciados e depende da mesma formação discursiva, que, por sua vez, necessita, para ser minimamente efetivo, um conjunto de "condições de existência" ou "condições de possibilidade", para cuja criação, ao mesmo tempo, contribui. Dessa forma, o discurso geopolítico poderia se situar ao lado de outros que Foucault trabalhou, como o discurso clínico, o discurso da história das idéias no Ocidente e o discurso psiquiátrico.

Edward Said (1993) também apela para a necessidade de localizar o texto, a linguagem, no mundo. As circunstâncias históricas em que surgem os produtos culturais são inseparáveis desses produtos. A representação do mundo é construída de tal forma, que se estabelecem valores e hierarquias para justificar políticas (por exemplo, coloniais e de extermínio). E essa representação chega às pessoas tanto através de doutrinas políticas como de obras literárias, musicais, pictóricas... De tal maneira, por exemplo, que não se pode compreender a natureza do imperialismo sem estudar os textos, discursos e metáforas das relações coloniais, dado que o imperialismo é algo mais que dominação política ou econômica.

Em suma, os discursos geopolíticos são inseparáveis das (e estão constituídos pelas) representações e as práticas geopolíticas. Dessas últimas derivam seu poder, ao mesmo tempo que condicionam sua inteligibilidade.

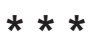

Este dossiê se constituiu com este pano de fundo, o de construir uma geopolítica crítica da 
América Latina, que se ocupe não somente das práticas e representações espaciais dos Estados, mas que tome as práticas e representações espaciais dos movimentos sociais como a possibilidade certa de desafiar o poder geopolítico dos Estados e as representações dos intelectuais de Estado. Em suma, explorar a constituição espacial dos mecanismos do poder na América Latina e a cartografia das resistências a esse poder.

O artigo de John Agnew, que abre o dossiê, apresenta os traços básicos das relações de poder no atual sistema mundial. $\mathrm{O}$ autor aborda a questão discutindo qual é a melhor caracterização da posição dos Estados Unidos no mundo: potência imperial ou potência hegemônica. E conclui que a melhor forma de denominar o momento atual é hegemonia, entendida não somente como uma capacidade de exercer um poder de coerção sem limites, mas como a capacidade, reconhecida pelo resto dos atores, de definir as regras do jogo. A globalidade do poder não é nova; o novo, segundo Agnew, é a combinação de redes globais e fragmentação territorial localizada, como mostram, por exemplo, as agudas variações locais em crescimento econômico. O trabalho de Agnew é o ponto de partida necessário para se entender o lugar ocupado pela América Latina na nova ordem mundial que emergiu após o fim da Guerra Fria.

Explorar como a América Latina foi "situada" nos modelos geopolíticos globais, elaborados fundamentalmente por intelectuais do Estado, europeus e norte-americanos, é o objetivo do trabalho de Heriberto Cairo. Nos modelos de Halford T. Mackinder, que foram tão influentes - e ainda têm adeptos - ao longo do século XX, a América Latina ocupava uma posição marginal dentro do campo de ação natural de potência marítima. $\mathrm{Na}$ geopolítica ideológica, característica da ordem geopolítica da Guerra Fria, o papel da América Latina não deixou de ser o de um tabuleiro passivo na disputa das duas superpotências. Na nova era geopolítica, a América Latina vai se delineando com contornos próprios, os quais, em algumas ocasiões, são marcados como zonas de perigo.
Walter Mignolo, fundamentado em algumas críticas e comentários da sua influente obra, $L a$ idea de América Latina, expõe alguns dos principais traços do projeto modernidade e colonialidade na América Latina, um projeto que procura desprender-se do eurocentrismo que se manifesta na colonialidade do poder e do saber na América Latina - e em outras regiões do mundo. A América Latina, sustenta Mignolo, é uma região construída pelos europeus na segunda modernidade - do mesmo modo que a América se construiu na primeira modernidade, do domínio ibérico -, sobre a base da exclusão e do silenciamento de indígenas e afro-latinos. A opção des-colonial se construiu na fronteira. O pensamento des-colonial é o pensamento fronteiriço, e há de procurar, segundo Mignolo, sua genealogia não na Grécia clássica, mas nos tratados des-coloniais que surgem a partir do encontro com os europeus, ou melhor, das resistências à dominação européia.

O trabalho de Jaime Preciado explora, a partir da perspectiva analítica dos sistemas-mundo, a situação da América Latina e os processos de configuração de semiperiferias na região: a subordinada, como o México; a com aspirações de potência global, como o Brasil; e a anti-hegemônica, como a da Venezuela. Revisa o estado dos processos de integração e alianças na região e termina apresentando o papel dos atores transnacionais da sociedade civil nesse novo mapa da área.

Breno Bringel e Alfredo Falero, a partir de um diálogo integrador das perspectivas geográfica e sociológica que reconsidera a importância do lugar nas análises sociais, fazem um estudo sobre como os movimentos sociais na América Latina tecem redes transnacionais. Em particular, ocupam-se de dois movimentos: o Movimento dos Trabalhadores Rurais Sem Terra (MST) brasileiro e a Federação Uruguaia de Cooperativas de Moradia por Ajuda Mútua (FUCVAM). Mostram como os anos 1990 são decisivos na configuração dessas redes que desafiam os Estadosnação existentes e constroem novas territorialidades, vinculadas, por exemplo, ao desenvolvimento de uma integração a partir de 
baixo. Ocupam-se não somente dos aspectos materiais desses processos (as práticas espaciais), mas também dos simbólicos (as representações do espaço). Talvez uma das contribuições mais importantes do trabalho de Bringel e Falero seja mostrar que esses processos "anti-geopolíticos" não são meras resistências internas em cada Estado ou na região, mas contribuem para reinscrever a América Latina no mundo, como mostra o caso da relação entre o MST e a Via Campesina.

Carlos Milani aborda uma temática similar. Também analisa os movimentos sociais latino-americanos, nesse caso, os ambientalistas. Através desse estudo, o autor desconstrói o pretendido caráter natural do sistema interestatal e mostra como os problemas ambientais e os movimentos ambientalistas desafiam o conceito de soberania dos Estados. Mostra a inserção desses movimentos no movimento "altermundista" global, estudando, em particular o caso do Fórum Social Mundial, no qual fica clara a relevância global dos movimentos latino-americanos, no momento de definir políticas como a de impulsionar avanços críticos na ação. É importante destacar a contribuição do trabalho de Milani no tocante a entender os processos de re-territorialização dos sujeitos, num mundo, ainda de Estados-nação.

Para terminar, volto ao princípio e retomo García Canclini. Seu ensaio conclui com a enumeração de uma série de tarefas "que poderiam contribuir para que a América Latina se reconstitua como região, localizando-se mais criativa e competitivamente nos intercâmbios globais" (García Canclini, 2002, p. 94-95): identificar as áreas estratégicas de desenvolvimento; desenvolver práticas socioculturais participativas, multiculturais e promovedoras do avanço tecnológico; re-localizar as práticas culturais entre o endógeno e o internacional; e cultivar e proteger a diversidade latinoamericana. Em suma, García Canclini recomenda negociar melhor o lugar da América Latina num mundo globalizado, tendo em conta suas peculia- ridades culturais.

Mas talvez já não seja o momento dessa operação. Como afirma Walter Mignolo, na conclusão de seu livro La idea de América Latina,

... para o imaginário continental do futuro, dar a volta ao continente não será a solução. Mudar o conteúdo sem questionar a lógica que o sustenta é necessário, porém está muito longe de ser suficiente. Uma 'epistemologia do Sul' seria um segundo passo para apagar a lembrança de um planeta dividido em quatro continentes e promover um processo de pensamento fronteiriço crítico (2007, p. 181).

E esse pensamento somente poderá ser, nas palavras de Boaventura de Sousa Santos (2007), "pós-abismal", ou seja, capaz de superar o monopólio da ciência ocidental, para distinguir, entre o verdadeiro e o falso, a exclusão dos saberes que estão "do outro lado da linha".

Então, talvez também - e somente talvez -, estejamos no momento de "desmontar" a idéia da América Latina que se criou como "parte desse processo expansivo universal [da segunda modernidade]" (Mignolo, 2007, p. 217), e da construção de um "depois da América Latina”, parte do Sul global, do qual, por certo, a Europa meridional não tem razão para se excluir.

\section{REFERÊNCIAS}

AGNEW, John. Geopolitics: Re-visioning World Politics, $2^{\mathrm{a}}$ edição, Londres, Routledge, 2003 [trad. ao espanhol por M. D. Lois Barrio. Geopolítica: Una re-visión de la política mundial. Madrid, Trama Editorial, 2005].

AGNEW, John., e CORBRIDGE, Stuart. Mastering Space: Hegemony, Territory and International Political Economy, Londres, Routledge, 1995.

DALBY, Simon. Creating the Second Cold War: The Discourse of Politics, Londres, Pinter, 1990.

DODDS, Klaus. Steve Bell's eye: cartoons, popular geopolitics and the War on Terror. Security Dialogue, 38, 2007, p. 157-177.

FOUCAULT, Michel. Naissance de la clinique: une archéologie du regard médical, París, P.U.F., 1963.

FOUCAULT, Michel. Histoire de la sexualité 1. La volonté de savoir, París, Gallimard, 1976.

GARCÍA CANCLINI, Néstor. Latinoamericanos buscando lugar en este siglo. Buenos Aires, Paidós, 2002.

LANDER, Edgardo (Org.) A colonialidade do saber. Eurocentrismo e ciências sociais. Buenos Aires: CLACSO, 2005. 
LEFEBVRE, Henri. La production de l'espace, París, Anthropos, 1974.

MIGNOLO, Walter. La idea de América Latina. La herida colonial y la opción decolonial, Barcelona, Gedisa, 2007.

Ó TUATHAIL, Géaroid. Critical Geopolitics, Londres, Routledge, 1996.

ROUTLEDGE, Paul. Anti-geopolitics. Introduction. In:

G. O Tuathail, S. Dalby e P. Routledge (eds.) The Geopolitics Reader. Londres, Routledge, 1998, p.245-255.
SAID, Edward. Culture and Imperialism, Nueva York, Knopf, 1993.

SANTOS, Boaventura de Sousa. Beyond Abyssal Thinking: From Global Lines to Ecologies of Knowledges. Review, 30 (1), 2007, p. 45-990.

SHARP, Joanne. Refiguring geopolitics: the Reader's Digest and popular geographies of danger at the end of the Cold War. In: K. Dodds e D. Atkinson (eds.) Geopolitical Traditions. Londres, Routledge, 2000, p. 332-352. 